Disponível em: $\underline{\text { http://periodicos.ufpb.br/ojs2/index.php/recfin }}$

\title{
JEITINHO BRASILEIRO, CORRUPÇÃO E CONTABILIDADE ${ }^{1}$
}

\author{
BRAZILIAN WAY, CORRUPTION AND ACCOUNTING
}

\author{
João Gabriel Nascimento de Araújo \\ Doutorando e Mestre em Ciências Contábeis (UFPE) \\ j_gabriel90@hotmail.com \\ Tiago de Moura Soeiro \\ Doutorando e Mestre em Ciências Contábeis (UFPE) \\ tiago-soeiro@hotmail.com \\ Francisco José Sobreira de Matos \\ Doutorando em Filosofia (UFPE/UFRN/UFPB) \\ franzeh@hotmail.com \\ Diana Carolina Gomez Bautista \\ Doutoranda em Desenvolvimento e Meio Ambiente (UFPE) \\ dianacaro.gomez@gmail.com
}

\section{RESUMO}

Objetivo: Neste ensaio pretendemos apresentar uma discussão acerca da relação entre corrupção em contabilidade e o "jeitinho brasileiro", e suas implicações.

Fundamento: Fundamentamos nosso trabalho em dois pontos: iniciamos nossa discussão conceituando "cultura e jeitinho brasileiro", amparados em trabalhos como Hollanda (1936), Da Matta (1984) e Chauí (2000); em seguida trazemos fundamentação sobre a corrupção na contabilidade, fundamentando os argumentos principalmente nos trabalhos de Borini e Grisi (2009) e Consenza (2015).

Método: Ensaio teórico.

Resultados: Nossa tese é que o jeitinho brasileiro exerce influência na corrupção nos negócios e na contabilidade.

Contribuições: Entendemos que pesquisas futuras podem focar, por exemplo, em: (i) como os sistemas de controle gerencial são influenciados pela percepção dos gestores sobre o "jeitinho brasileiro"; (ii) analisar como os sistemas de controle gerencial são estruturados/modificados aos aspectos do "jeitinho brasileiro"; (iii) analisar como o jeitinho brasileiro é suprimido ou potencializado para ser utilizado a favor do negócio; e (iv) averiguar a dissonância cognitiva e identificar contradições e conflitos de identidade e a utilização do "jeitinho brasileiro" como esquiva a estas incoerências cotidianas no contexto organizacional.

\footnotetext{
${ }^{1}$ Artigo recebido em: 16/09/2019. Revisado por pares em: 09/01/2020. Reformulado em: 19/04/2020. Recomendado para publicação: 19/04/2020 por Karla Katiúscia Nóbrega de Almeida (Editora Adjunta). Publicado em: 25/05/2020. Organização responsável pelo periódico: UFPB
} 
Palavras-chave: Cultura. Jeitinho brasileiro. Corrupção. Contabilidade.

\section{ABSTRACT}

Objective: In this essay we intend to present a discussion about the relationship between accounting corruption and the "Brazilian way", and its implications.

Grounding: We base our work on two points: we started our discussion by conceptualizing "culture and brazilian way", supported by works such as Hollanda (1936), Da Matta (1984) and Chauí (2000); then we bring a rationale about accounting corruption, grounding the arguments mainly in the works of Borini and Grisi (2009) and Consenza (2015).

Method: Theoretical essay.

Results: Our thesis is that the Brazilian way has an influence on business and accounting corruption.

Contributions: We understand that future research may focus, for example, on: (i) how management control systems are influenced by managers' perceptions of the "Brazilian way"; (ii) analyze how management control systems are structured / modified to the "Brazilian way" aspects; (iii) analyze how the Brazilian way is suppressed or enhanced to be used in favor of the business; and (iv) investigate cognitive dissonance and identify contradictions and conflicts of identity and the use of the "Brazilian way" as a way of avoiding these daily inconsistencies in the organizational context.

Keywords: Culture. Brazilian way. Corruption. Accounting.

\section{INTRODUÇÃO}

As culturas se mantêm dos seus símbolos, signos e relações. Estas teias de significado necessitam de uma efetivação cotidiana dos indivíduos participantes destas culturas para sua afirmação, reprodução e pungência, que por sua vez, apresentam-se ao indivíduo como fontes e parâmetros primevos para o compreender e interpretar dos fenômenos do mundo (Geertz, 1989).

Um traço marcante do nosso tempo é a corrupção, surgida em decorrência da ambição do indivíduo em acumular riqueza. A corrupção pode ser entendida como práticas ilícitas em prol de si mesmo e/ou de um coletivo (Araújo, 2014; Branco \& Delgado, 2012). Entretanto, não se trata de um fenômeno específico em determinada localização e/ou temporalidade. Pelo contrário, é legado de uma dimensão social, moral, ética, legal, histórica e cultural. Entretanto, uma determinada atitude ou comportamento pode ser conceituado ou não como corrupção a depender de diversos fatores políticos, econômicos e sociais (Albrecht, Malagueño, Holland, \& Sanders, 2012).

Em se tratando especificamente do Brasil, uma característica cultural popularmente conhecida e disseminada por "jeitinho" ou "jeitinho brasileiro". Segundo dados de pesquisa recente com 1200 brasileiros de 72 municípios, 91\% dos entrevistados já ouviram falar sobre o "jeitinho brasileiro", sendo que $74 \%$ já fizeram uso deste aspecto para resolver alguma problemática cotidiana (IPSOS, 2016). Em outra pesquisa sobre o modo de agir dos brasileiros, $82 \%$ dos entrevistados acreditam a maioria age querendo tirar vantagem, enquanto só $16 \%$ dos entrevistados acham que as pessoas agem de maneira correta (GLOBO, 2014).

O "jeitinho brasileiro" está associado não só a uma pluralidade conceitual com aspectos percebidos como positivos ou negativos, como é traço fundamental para análise de conteúdos fundamentais da cultura, dada sua quase universalidade. Por exemplo, Pedroso, MassukadoNakatani, and Mussi (2009), com base na prévia literatura à respeito do conceito do "jeitinho brasileiro", dividiram-no em dimensões em positivas e negativas. Dentre os aspectos positivos do "jeitinho brasileiro", destaca-se criatividade e inovação, iniciativa para mudanças e habilidade de resolução de problemas, habilidade de persuasão e conciliação (negociação), adaptabilidade e 
flexibilidade, habilidade no relacionamento pessoal, e capacidade de improvisação. Por outro lado, como aspectos negativos cita-se a tendência à inadequação as normas, tendência ao uso do recurso do poder, alienação, e propensão à corrupção/práticas de corrupção.

Nesse contexto, Da Matta (1984) afirma que há um verdadeiro combate entre leis que devem valer para todos, e relações que evidentemente só podem funcionar para quem as tem. O resultado é um sistema social dividido e equilibrado entre duas unidades sociais básicas: o indivíduo (o sujeito das leis universais) e a pessoa (o sujeito das relações sociais). Da Matta (1984) afirma ainda que entre o indivíduo e o sujeito reside o "jeitinho", a forma que o brasileiro encontrou de enfrentar as contradições e paradoxos dessa relação.

Exceto quando escândalos vêm à tona, é difícil mensurar níveis de práticas de corrupção no ambiente corporativo. Entretanto, Araújo (2014) afirma que o nível de corrupção da sociedade pode fornecer um indício. Em estudo da ONG Transparência Internacional (2015), o Brasil aparece em $76^{\circ}$ lugar num ranking de percepção da corrupção, ao lado de Bósnia e Herzegovina, Burkina Faso, Índia, Tailândia, Tunísia e Zâmbia.

Colocando a discussão da corrupção no campo da contabilidade, é possível afirmar que esta aparece frequentemente em forma de fraudes, que, por vezes, recebe a alcunha de "contabilidade criativa". Tal termo já foi conceituado por autores como Cosenza \& Grateron (2003); Gadea \& Gastón (1999) e Lang (1998), e há um certo consenso que se trata de um termo geralmente utilizado para práticas decorrentes de brechas e flexibilidades normativas que visam apresentar o resultado mais adequado para a entidade, ainda que não sejam valores condizentes com a realidade, ou seja, informações à margem da legalidade e da moralidade.

De acordo com Mayoral (2000) existem três grupos de objetivos que levam as empresas a se utilizarem da contabilidade criativa: 1) melhorar a imagem da empresa; 2) estabilizar a imagem da empresa e 3) debilitar a imagem da empresa. Em complemento, Cosenza and Grateron (2003) apresentam três grandes motivações para sua prática: 1) influenciar no resultado contábil, 2) necessidades contratuais e 3 ) interesses políticos e sociais.

Apesar de haver uma quantidade significativa de trabalhos que examinam o efeito da cultura nas organizações, ainda se carece de melhores explicações sobre como o jeitinho brasileiro permeia as atividades organizacionais. Desta forma, com base na relevância do tema corrupção, e sua relação por vezes íntima com a contabilidade e o ambiente de negócios, uma questão antiga que vem se tornando presente no dia-a-dia da sociedade através dos noticiários nos últimos anos e décadas, neste ensaio pretendemos apresentar uma discussão acerca da problemática e suas implicações. Assim, iniciaremos nossa discussão conceituando "cultura". Em seguida visamos sustentar que cultura influencia os pensamentos e ações das pessoas criadas nessa cultura. Neste sentido, ao tratarmos de cultura brasileira, discutiremos sobre o traço marcante que conhecemos como o jeitinho brasileiro, e como esse jeitinho torna os indivíduos tolerantes até atitudes criminosas, como a corrupção. Assim sendo, nossa tese é que o jeitinho brasileiro exerce influência a corrupção nos negócios e na contabilidade.

\section{CULTURA E JEITINHO BRASILEIRO}

A cultura implica um conjunto de normas sociais, valores e crenças que são compartilhadas pelos membros de um grupo e influenciam suas ações (Fisher, 1995). Crenças e valores compartilhados podem influenciar as ações das pessoas dentro de uma organização, o que poderia caracterizar a cultura como uma fonte de pressão extra-organizacional sujeita a uma resposta estratégica (Oliver, 1991).

Entretanto, para se estudar seus efeitos, não podemos desconsiderar a sua dimensão simbólica. Isto implica em considerar que o ser humano é um animal amarrado as suas teias de significado que ele mesmo produziu. Esta especificidade humana é a característica que melhor define 
nossa diferença diante dos demais seres. Este horizonte de significado é fruto da própria constância e acúmulo de saberes, memórias e interpretações resultantes dos nossos atos no mundo. Desta forma, somos o único ser que pensa regras, normas e conceitos, e que buscam construir sua realidade a partir destas leis (Geertz, 1989). Estas teias de relação e suas interpretações é o que Geertz (1989) chama de Cultura.

O conceito de cultura apresenta conteúdo fundamental para explicação não só do que entendemos pelo significado do ser humano, como para uma composição interpretativa de suas ações, uma vez que entendida como mundo objetivo de realidades simbolicamente significadas e que tende, pela tradição, a perpetuar-se no tempo. A cultura mostra toda uma face voltada para o dever-ser do indivíduo e não apenas para a continuação do seu ser, dado que o indivíduo encontra na cultura, não apenas o aspecto técnico instrumental que facilita sua sobrevivência, como a própria sistemática interna do seu processo normativo de autorrealização. (Vaz, 1988).

Ou seja, entender aspectos fundamentais da cultura a ser estudada é compreender não só as estratégias de sobrevivência de cada sociedade, mas seus próprios conteúdos simbólicos, valorações, disposições de ser e agir considerados como objetivos, como a própria forma ulterior do que significa normalidade para determinada sociedade. A cultura ocorre na mediação dos indivíduos entre si, manipulando padrões designificados que fazem sentido num contexto específico.

Assim, “o comportamento humano é visto como ação simbólica" (Geertz, 1989, p. 20). Já que "nós somos animais incompletos e inacabados que nos completamos e acabamos através da cultura - não através da cultura em geral, mas através de formas altamente particulares de cultura (...)" (Geertz, 1989, p. 61). Podendo, pois, o pesquisador, valorar e medir cada componente cultural e sua importância no estudo da medida de sua influência e efetividade na teia de significados e interpretações que compõem cada cultura.

Desta forma, em se tratando de cultura brasileira uma característica distintiva é o jeitinho. Este traço marcante da cultura nacional, conforme Gomes (1977), decorre da maneira que o brasileiro encontrou de desrespeitar a extrema formalidade nas relações. Não necessariamente esse traço cultural é algo ruim, porém, quando associado a atitudes que buscam encontrar um meio termo entre o "pode" e o "não pode" normativo, esse "jeitinho" se associa ao que Da Matta (1984) chama de malandragem. O jeitinho pode ainda ser entendido como:

(...) um modo e um estilo de realizar. Mas que modo é esse? É lógico que ele indica algo importante. É, sobretudo, um modo simpático, desesperado ou humano de relacionar o impessoal com o pessoal; nos casos - ou no caso - de permitir juntar um problema pessoal (atraso, falta de dinheiro, ignorância das leis por falta de divulgação, confusão legal, ambiguidade do texto da lei, má vontade do agente da norma ou do usuário, injustiça da própria lei, feita para uma dada situação, mas aplicada universalmente etc.) com um problema impessoal. Em geral, o jeito é um modo pacífico e até mesmo legítimo de resolver tais problemas, provocando essa junção inteiramente casuística da lei com a pessoa que a está utilizando (Da Matta, 1984, p. 99).

O jeitinho brasileiro é considerado como um traço marcante da cultura brasileira, dado sua disseminação, reprodução e influência nos indivíduos e nas teias de significado e interpretações desta cultura. A este respeito, alguns dados suportam esta conclusão. Segundo pesquisa (IPSOS, 2016) $91 \%$ dos entrevistados já ouviram falar sobre o "jeitinho brasileiro", sendo que $74 \%$ já fizeram uso deste aspecto para resolver alguma problemática cotidiana, e $62 \%$ é a porcentagem de respondentes que na prática se utilizaram do jeitinho na resolução de alguma problemática no ano anterior. Ainda segundo esta pesquisa, para $82 \%$ dos entrevistados, para que as coisas funcionem, é preciso que todos cumpram a lei, e que para $64 \%$, quando alguém deseja para si um tra- 
tamento diferente da lei, está prejudicando a sociedade. Porém, para quatro em cada dez entrevistados (43\%), toda lei precisa de exceções e, para mais de um terço dos pesquisados (36\%), é possível passar por cima das leis com uma boa conversa.

Em outra pesquisa (GLOBO, 2014) sobre o modo de agir dos brasileiros, $82 \%$ dos entrevistados acreditam a maioria dos brasileiros agem querendo tirar vantagem, enquanto só $16 \%$ dos entrevistados acham que as pessoas agem de maneira correta. Na mesma pesquisa, $62 \%$ dos brasileiros apontam que não têm nenhuma (29\%) ou quase nenhuma confiança (33\%) na maioria das pessoas. Os otimistas, que confiam muito no próximo, são apenas $6 \%$, e os que disseram ter alguma confiança são $31 \%$.

$\mathrm{O}$ "jeitinho" pode ser explicado, ainda, pela aversão do brasileiro à radicalidades, sempre buscando uma forma de conciliar oposições, ainda que isso leve a posição nenhuma. Conciliador e obediente, cordial, o brasileiro jamais conduz as tensões àquele nível em que geram um limite sem retorno (Gomes, 1977).

Sobre isso, Motta e Alcadipani (1999) atribuem o surgimento do "jeitinho brasileiro" à época do Brasil colônia, onde as leis criadas pela coroa portuguesa não eram pensadas para os brasileiros, mas sim para os lusitanos e luso-brasileiros, fazendo surgirem comportamentos em que se evitam as regras, leis e normas, que são vistas como extremas e não adequadas à realidade local. Desta forma, conforme Holanda (1936), o brasileiro, homem cordial que é, buscava formas de mostrar como a situação era injusta para o seu caso e assim conseguir o que almejava.

Nesse sentido, Da Matta (1984) coloca que entre o "pode" e o "não pode", o brasileiro escolheu uma junção entre os dois, e é essa junção que produz todos os tipos de "jeitinhos" e arranjos, que fazem com que seja possível operar um sistema legal que quase sempre nada tem a ver com a realidade social.

Esse aspecto cultural brasileiro está ligado ao que Chauí (2000) chama de mito fundador, que faz com que apesar de brasileiros tolerarem e até mesmo cometerem atitudes criminosas, consiga sentir orgulho de ser brasileiro. Para Chauí (2000) um mito fundador é aquele que não cessa de encontrar novos meios para exprimir-se, novas linguagens, novos valores e ideias, de tal modo que, quanto mais parece ser outra coisa, tanto mais é a repetição de si mesmo.

Ainda segundo Chauí (2000), o mito fundador que dá suporte ao "jeitinho brasileiro" é o fenômeno do "verdeamarelismo" que tem sua origem na colonização do Brasil e de como a sociedade e economia brasileira se organizaram. $\mathrm{O}$ "verdeamarelismo" pode ser compreendido, conforme Singer (1998) e Furtado (1999), em suas origens da sociedade na América Latina, com classes dominantes e dominadas bem definidas e consideradas como algo natural. Dessa naturalidade nas relações surge o mito fundador de que alguns atos são considerados como normais e aceitáveis ou justificáveis, tais como desigualdade social, racial e de gênero. Surge nesse meio o "jeitinho", como forma de justificar o arranjo social.

Um fator importante a ser analisado é a influência do jeitinho brasileiro nos conceitos e interpretações do que é público e privado na sociedade brasileira. O nosso processo histórico de construção da civilização claramente apresenta-se numa progressiva guinada para os interesses individuais em detrimento das questões coletivas e de bem comum. A esfera privada historicamente teve ampla primazia sobre o público, deixando marcas profundas na nossa cultura.

Como resultado dessa herança, vemos obliterado o reconhecimento e consciência do direito à cidadania. Bom retrato dessas características são os costumes e frases que, incorporadas ao nosso cotidiano, apresentam-se como faceta do patrimonialismo que marca nossa cultura: o "jeitinho", a noção de que "o melhor é levar vantagem em tudo, certo?", as formas de resolver conflitos pautadas no bordão "você sabe com quem está falando?" (Zanella, 2008, p. 87). 
O patrimonialismo brasileiro não se resume apenas ao Estado, mas aparece como traço marcante de toda sociedade brasileira. De acordo com Hollanda (1936), esse patrimonialismo é o resultado de uma cultura da personalidade, em que as regras da esfera privada predominam na mediação das relações entre indivíduo, sociedade e Estado. No Brasil imperaria “(...) certa incapacidade, que se diria congênita, de fazer prevalecer qualquer forma de ordenação impessoal e mecânica sobre as relações de caráter orgânico e comunal, como o são as que se fundam no parentesco, na vizinhança e na amizade" (Holanda, 1936, p. 137).

Tendo em vista essas múltiplas camadas que compõem a teia cultural brasileira que aparecem como fenômenos influenciados por aspectos negativos do jeitinho brasileiro - traço fundamental da cultura nacional -, cria um dito desconexo, um círculo vicioso, sedimentado na ideia do faça o que digo, mas não faça o que faço, uma distopia real, em que a crença no correto, na lei, na ordem e na ética são quase que consensos, mas que na prática funciona como que em dissonância, onde indivíduos manifestam seu exato oposto na maioria das ações e escolhas do cotidiano. Este escarcéu simbólico entre teoria/prática, privado/público e ético/antiético que hierarquizam estruturas importantes de significação é aqui tratado como conteúdo fundamental para análise dos conteúdos, ações e teorias que buscam entender o contexto brasileiro.

\section{CORRUPÇÃO EM CONTABILIDADE}

Ao mediar entre o "pode" e o "não pode", o jeitinho abre caminhos para arranjos que fazem com que seja possível operar um sistema legal que quase sempre nada tem a ver com a realidade social, tornando-nos tolerantes até atitudes criminosas, como a corrupção. Desta forma, nesta seção, visamos discutir sobre como a cultura local influência nas ações e pensamentos dos atores, ou seja, como o jeitinho atua como um filtro epistemológico na reflexividade dos atores à respeito dos significados das ações. Porém, antes de iniciarmos tal discussão, vamos inicialmente avaliar a dimensão da corrupção presente em alguns estudos empíricos.

Em se tratando especificamente de corrupção, este assunto vem sendo discutido empiricamente apontando que as formas mais praticadas no ambiente empresarial são o suborno, propina, tráfico de informações e fraudes (Araújo, 2014). Nesse sentido, Ackerman (1978) aponta que esse fato ocorre frequentemente tanto na relação do sujeito com o ente público, quanto do sujeito com o ente privado.

No âmbito público, a relação ocorre quando o sujeito recebe incentivo (geralmente financeiro) e põe outros interesses acima do interesse público, desvirtuando o sistema burocrático ideal. De forma similar, no ambiente privado, quando o funcionário se corrompe desvirtua a maximização de esforços esperada (Araújo, 2014; Granovetter, 2006). Assim, conforme Filgueiras (2009, p. 397):

A corrupção, para além da questão propriamente monetária e contábil, está relacionada a processos sociais que levam em consideração valores e normas que, além do institucional e do formal, consideram aspectos informais e culturais. A análise da corrupção deve atender a esses aspectos sociológicos implicados no reconhecimento de normas formais e informais, porquanto a passagem do privado ao público ocorre em meio a configurações de valores e normas.

Conforme Borini and Grisi (2009) e Araújo (2014), a articulação de um ambiente corrupto depende de três fatores: a inadequada mobilização dos recursos e capacidades para atividades que gerem mais recursos do que a prática ilícita; inadequada seleção de mão-de-obra; e a institucionalização de um ambiente corporativo com normas socializadas que não estimulam nem reprimem as práticas ilegais. 
Nesse contexto, Borini and Grisi (2009) desenvolveram um questionário, também utilizado por Araújo (2014), com as principais práticas ilícitas praticadas no âmbito empresarial, dividida em Fatores, conforme o Quadro 1.

Quadro 1 - Práticas e Fatores de Corrupção no Ambiente de Negócios

\begin{tabular}{|c|c|}
\hline PRÁTICAS & FATORES \\
\hline Prática de oferecer dinheiro para a fiscalização para obter um serviço especial & \multirow{5}{*}{ Suborno } \\
\hline Prática de oferecer dinheiro para não ser multado em uma transgressão & \\
\hline Prática de oferecer dinheiro para obter vantagem & \\
\hline Prática de oferecer dinheiro ao fiscal para garantir uma licença & \\
\hline Prática de oferecer dinheiro para o fornecedor & \\
\hline Receptação de mercadoria de carga roubada & \multirow{8}{*}{ Roubo } \\
\hline Simulação de roubo para obtenção do seguro & \\
\hline Fechamento de negócio por lavagem de dinheiro & \\
\hline Adquirir cargas roubadas sem saber que é roubada & \\
\hline Apreensão de mercadorias por suspeita de desvio & \\
\hline Compra de mercadorias desviadas & \\
\hline Fornecedores com nomes envolvidos em casos de corrupção & \\
\hline Lavagem de dinheiro & \\
\hline Descontos por meio do faturamento sem impostos & \multirow{7}{*}{ Sonegação } \\
\hline Venda de mercadorias sem nota fiscal por fornecedores & \\
\hline Venda de mercadorias sem nota fiscal por concorrentes & \\
\hline Manutenção do caixa-dois & \\
\hline Sonegação de impostos & \\
\hline Compra de produtos sem nota fiscal pelos concorrentes & \\
\hline Prática de subfaturamento & \\
\hline Ofertas de informações sigilosas de concorrentes & \multirow{4}{*}{$\begin{array}{l}\text { Tráfico de } \\
\text { Informação }\end{array}$} \\
\hline Compra de informações sigilosas de outras empresas & \\
\hline Conhecimento do lançamento de produtos antes da divulgação oficial & \\
\hline Venda de produtos cujas especificações são diferentes das anunciadas & \\
\hline Compra e venda de produtos pirata & \multirow{5}{*}{ Pirataria } \\
\hline Venda de produtos com qualidade inferior & \\
\hline Venda de produtos com valor muito abaixo do mercado & \\
\hline Venda de produtos com informações omitidas & \\
\hline Omissão de informações & \\
\hline Existe concorrência desleal & \multirow{3}{*}{$\begin{array}{c}\text { Concorrência } \\
\text { Desleal }\end{array}$} \\
\hline Venda de produtos a preço muito abaixo do custo médio & \\
\hline Fechamento de empresas devido a agir de forma desleal & \\
\hline Propina para fechar negócios & \multirow[t]{2}{*}{ Propina } \\
\hline Pagamento de propina para fiscais do governo & \\
\hline Pagamento antecipado ao fornecedor e não recebimento da mercadoria exata & \multirow[t]{2}{*}{ Fraude } \\
\hline Fraude interna praticada por funcionários & \\
\hline
\end{tabular}

Fonte: Borini and Grisi (2009)

Especificamente sobre corrupção em contabilidade, ela aparece frequentemente em forma de fraudes, através das denominadas práticas de contabilidade criativa. Contabilidade criativa já foi conceituada por diversos autores (Cosenza \& Grateron, 2003; Gadea \& Gastón, 1999; Lang, 1998) desde o início dos anos de 1980, e é um termo geralmente utilizado para práticas decorrentes de brechas e flexibilidades normativas que visam apresentar o resultado mais adequado para a entidade, ainda que não sejam valores condizentes (e nem mesmo aproximados) com a realidade. 
Conforme Mayoral (2000) existem três grupos de objetivos que levam as empresas a se utilizarem da contabilidade criativa: 1) melhorar a imagem da empresa; 2) estabilizar a imagem da empresa e 3) debilitar a imagem da empresa. Por sua vez, Cosenza and Grateron (2003) apresentam três grandes motivações para sua prática: 1) influenciar no resultado contábil, 2) necessidades contratuais e 3) interesses políticos e sociais. Cada uma das três motivações, por sua vez, é guiada por uma das três políticas contábeis: 1) agressiva, 2) conservadora e 3) maquiadora. O quadro 2 apresenta as definições de Cosenza (2015).

Quadro 2 - Motivações e consequências da contabilidade criativa

\begin{tabular}{|c|c|c|}
\hline MOTIVAÇÃO & OPERACIONALIZAÇÃO & CONSEQUÊNCIAS \\
\hline $\begin{array}{l}\text { Influenciar no } \\
\text { resultado } \\
\text { contábil }\end{array}$ & $\begin{array}{l}\text { Incremento ou estabilização do } \\
\text { valor patrimonial da empresa } \\
\text { no mercado de capitais. } \\
\text { Diminuição das receitas ou } \\
\text { aumento das despesas e custos } \\
\text { de forma a reduzir os lucros pa- } \\
\text { ra sinalizar uma pior situação } \\
\text { ao mercado. } \\
\text { Estabiliza as receitas ou os lu- } \\
\text { cros para apresentar um menor } \\
\text { perfil de risco ao mercado. }\end{array}$ & $\begin{array}{l}\text { Avaliação positiva da gestão dos diri- } \\
\text { gentes. } \\
\text { Melhora a posição negociadora dos } \\
\text { contratos. } \\
\text { * Incrementa a remuneração dos diri- } \\
\text { gentes. } \\
\text { Apresenta uma situação crítica da em- } \\
\text { presa para tirar proveito no pagamen- } \\
\text { to de impostos. } \\
\text { Evita exigências salariais elevadas. } \\
\text { Oculta a situação real frente aos com- } \\
\text { petidores. }\end{array}$ \\
\hline $\begin{array}{c}\text { Necessidades } \\
\text { contratuais }\end{array}$ & $\begin{array}{l}\text { Mostrar bons indicadores de } \\
\text { rentabilidade, liquidez, solvência } \\
\text { e endividamento. } \\
\text { Mostra maus indicadores de } \\
\text { rentabilidade, liquidez, solvên- } \\
\text { cia e endividamento. } \\
\text { Redução dos picos de receitas } \\
\text { ou lucros, no sentido de poten- } \\
\text { cializar o nível } \\
\text { de confiança na empresa. }\end{array}$ & $\begin{array}{l}\text { Apresenta uma situação crítica da com- } \\
\text { panhia para tirar proveito no momento } \\
\text { da renegociação de contratos, tanto da } \\
\text { própria empresa como de remuneração } \\
\text { dos gerentes. } \\
\text { Poupança para assegurar futu- } \\
\text { ras remunerações. } \\
\text { Melhoras de posição na celebração de } \\
\text { contratos. }\end{array}$ \\
\hline $\begin{array}{l}\text { Interesses } \\
\text { políticos e } \\
\text { sociais }\end{array}$ & $\begin{array}{l}\text { Mostrar bons indicadores de } \\
\text { rentabilidade, liquidez, solvência } \\
\text { e endividamento. } \\
\text { Mostra maus indicadores de } \\
\text { rentabilidade, liquidez, solvên- } \\
\text { cia e endividamento. } \\
\text { Evita excessivas flutuações que } \\
\text { possam vir a deteriorar ou pre- } \\
\text { judicar a imagem social ou polí- } \\
\text { tica da empresa. }\end{array}$ & $\begin{array}{l}\text { Cumprimento das imposições legais. } \\
\text { Atendimento das exigências sociais. } \\
\text { Mostra uma situação crítica da empre- } \\
\text { sa para tirar proveito dos recursos pú- } \\
\text { blicos. } \\
\text { Minimiza as suspeitas de que a com- } \\
\text { panhia pratica o monopólio ou oligo- } \\
\text { pólio no mercado. } \\
\text { Permite pleitear aumento de tarifas } \\
\text { nos setores que estão sob regulação es- } \\
\text { tatal. }\end{array}$ \\
\hline
\end{tabular}

Fonte: Adaptado de Cosenza (2015)

A corrupção pode ser entendida como práticas ilícitas em prol de si mesmo e/ou de um coletivo e é legado de uma dimensão social, moral, ética, legal, histórica e cultural. Também podemos considerar a corrupção como uma experiência social sendo definida pelas atividades e conceitos sociais em que ela ocorre. A experiência social não é apenas internalizada intelectualmente, como também se inscreve em nossos corpos ao operar automaticamente como um hábito para guiar a ação.

Desta forma, cabe ressaltar que as ações são um elemento ativo da cultura, e desta forma, depende de processos culturais para sua realização, forma cultura e tem uma forma cultural. As- 
sim, ao ser considerada como um fenômeno cultural, assume-se que ela é um projeto histórico que deve ser realizado através da sociedade.

Entretanto a ação não é criada por meio de um acordo voluntário de indivíduos independentes. Na verdade, pode ser considerada como o engajamento temporariamente construído por atores de diferentes ambientes estruturais que, através da interação de hábito, imaginação e julgamento, reproduzem e transformam essas estruturas em resposta interativa aos problemas colocados pelas mudanças nas situações históricas (Emirbayer \& Mische, 1998).

Desta forma, podemos considerá-la como um fenômeno social, em que depende das relações sociais para sua realização. Portanto, ela forma relações sociais e tem uma forma social que as reflete. Além disso, constrói e promulga relações sociais porque ganha força ao cooperar com outras pessoas nas atividades da vida (Ratner, 1991). Desta forma, a ação precisa que as relações sociais se tornem reais (realizadas) e objetivas (objetivadas).

Sendo assim, a capacidade ou habilidade de um indivíduo agir de acordo com sua vontade é afetada pela estrutura cognitiva de crenças que ele formou ao longo de sua experiência de vida, e as percepções sustentadas pela sociedade e pelo indivíduo, das estruturas e circunstâncias do ambiente onde está e a posição onde este indivíduo nasceu, ou seja, é influenciada pela cultura. É nesse debate que se insere a prática da corrupção atenuada pela dissonância cognitiva do jeitinho brasileiro.

Entretanto, deve-se ter em mente que o jeitinho brasileiro possui desdobramentos positivos e negativos. Pedroso et al. (2009) destacaram como positivos: Criatividade e inovação; Iniciativa para mudança (de determinada situação) e habilidade de resolução de problemas; Habilidade de persuasão e conciliação (negociação); Adaptabilidade e flexibilidade; Habilidade no relacionamento pessoal; e Capacidade de improvisação. Por sua vez, como negativos: Tendência à inadequação a normas; Propensão a corromper ou a ser corrompido; Tendência ao uso de recurso de poder; e Alienação (tendência a se deixar ser manipulado).

Desta forma, o jeitinho pode ser incentivado e desincentivado dentro das organizações a depender, por exemplo, de que dimensão está sendo requisitada. Além disso, sem pretensão de ser taxativo, porém a título de exemplos, também pode exercer influência sobre da adoção do jeitinho e de suas dimensões: a cultura organizacional e seus valores, por ser permeada em partes pela cultura das pessoas que fazem parte dela (Jones, 2010); as características dos empreendedores, frente a sua aceitação ou aversão as dimensões do jeitinho (Pedroso et al., 2009); e sistemas de controles e práticas organizacionais (Flach, 2012).

Em relação ao desempenho da atividade e profissão contábil, por uma visão mais romântica, não se haveria espaço para o jeitinho brasileiro. Entretanto, desdobramentos positivos podem ser incentivados por aqueles que lidam em funções menos reguladas, como os contadores gerenciais e controllers, enquanto aqueles que lidam com a contabilidade societária e tributária não abririam espaço para nenhum jeitinho, uma vez que os riscos de incorrer em perdas financeiras ou prejudicar terceiros são iminentes. Na esfera pública, por sua vez, marcada por seus formalismos e/ou burocracias, a contabilidade deve seguir transparente e ética para com os seus usuários. Nota-se que os ramos da contabilidade podem fazer leituras distintas sobre o jeitinho e suas aplicações.

Entretanto, às vezes é possível que as regras do jogo, ou seja, que as regras e normas contábeis sejam seguidas e, mesmo assim, desviar-se de sua essência e/ou espírito ético, o que é conhecido como contabilidade criativa. A contabilidade criativa, apesar de seguir a legalidade é espúria e antiética. Porém não se confunde com corrupção, pois esta segunda, quando tratada nas relações humanas, refere-se uma atividade ilegal no qual se concede a vantagem para uns em detrimento de outros, como por exemplo, o suborno. Neste sentido, a contabilidade criativa pode ser entendida como uma expressão de corrupção quando houver atividade ilícita permeando sua 
essência, porém na sua ausência a contabilidade criativa é uma prática imoral, mas não ilegal, apesar dos efeitos potencialmente danosos a terceiros.

\section{CONSIDERAÇÕES FINAIS}

Desta forma, visando o aprofundamento do estudo da cultura e sua relação com práticas sociais, clamamos que nos estudos certa atenção seja dada às normas e práticas sociais, pois estas são frequentemente mantidas como uma explicação para os níveis de corrupção em um determinado país. O argumento para isto é relativamente simples: se a corrupção é parte da cultura e todos, ou quase, estão a praticando, ou seja, se "todo mundo faz", as chances de uma objeção moral são menores, e, com isso, esse comportamento tende a ser continuado.

Assim, práticas e atividades corruptas tornam-se institucionalizadas dentro das organizações, integrando-se ao cotidiano da vida organizacional (Brief, Buttram, \& Dukerich, 2001). Por exemplo, os líderes podem sancionar ou autorizar comportamentos corruptos, explícita ou implicitamente, impondo estruturas de recompensa que promovam práticas corruptas, ou tolerando ou ignorando tais práticas quando eles ocorrem (Ashforth \& Anand, 2003). Práticas corruptas, em seguida, tornam-se incorporadas nos scripts associados a funções organizacionais despersonalizadas, bem como nos processos organizacionais em andamento. Como resultado, práticas corruptas tornam-se rotineiras e habituais e, portanto, institucionalizadas dentro da organização.

Neste sentido, as atividades corruptas tornam-se menos salientes como corruptas, porque a rotinização as tornam normativas e executadas automaticamente. Na medida em que uma atividade continua saliente como corrupta, entre os novos membros da organização, por exemplo, ela se torna aceitável por meio de processos de socialização, sistemas de recompensa, ideologias, expectativas de obedecer a líderes e presunções de que as práticas existentes são racionais e legítimas.

Desta forma, o que chamamos de "prática informal" pode sociologicamente ser considerado de duas maneiras. Na primeira, a prática informal é inerente à cultura nacional, moldada por contextos históricos, sendo assim a cultura representa "valores", levando não apenas a certos comportamentos, mas também moldando as percepções culturais (Hofstede \& Bond, 1988). Na segunda, a prática informal é derivada da resistência popular contra outras normas sociais, que são impostas por novos governantes ou mudanças socioeconômicas e políticas (Hofstede, 2001; Kwok \& Tadesse, 2006).

Neste sentido, ao se estudar o jeitinho brasileiro cabe aos pesquisadores refletir e posicionar-se se o jeitinho brasileiro é uma dimensão cultural legítima específica do brasileiro ou é uma resposta às condições do seu ambiente circundante. Desta forma, para o primeiro caso, o jeitinho brasileiro é o perpetuador ou o pilar da institucionalização da corrupção, ou ainda, a corrupção seria/estaria embutida dentro da lógica do jeitinho brasileiro. Por outro lado, a corrupção seria uma resposta oportunista as condições do ambiente e nesse sentido, a categoria de análise do jeitinho brasileiro seria apenas uma classificação teórica para um comportamento previsível ou um padrão previsível.

Vale ressaltar que a pesquisa sobre corrupção e ética não nega a relevância dos interesses pessoais, oportunidades e as estruturas institucionais reguladoras de uma economia ou sociedade (Ashforth \& Anand, 2003; Treviño \& Weaver, 2003). Assim, a corrupção é entendida como refletindo uma série de fatores individuais e situacionais interagindo dentro das organizações e incluindo violações de princípios morais ou normas sociais, além de normas legais.

Desta forma, depreendemos duas implicações sobre o comportamento organizacional e a corrupção. Por um lado, o comportamento corrupto ou antiético em uma organização pode ser reduzido ou eliminado pela mudança cultural dentro da organização, envolvendo tanto elementos formais (por exemplo, sistemas de recompensa, iniciativas éticas formais) quanto elementos 
informais (por exemplo, comportamento de líder alterado), para que os membros da organização se identifiquem e se comprometer com altos padrões de comportamento (Treviño \& Weaver, 2003).

Por outro lado, a estrutura do comportamento organizacional também indica o quão profundamente o comportamento corrupto pode se tornar dentro de uma organização e dentro das estruturas normativas e cognitivas que orientam os pensamentos e ações dos membros da organização. Uma vez que a corrupção esteja profundamente enraizada, até mesmo choques exógenos como exposição na mídia ou intervenção governamental, ao mesmo tempo em que tornam as atividades corruptas salientes aos participantes, podem não ser suficientes para acabar com a corrupção (Ashforth \& Anand, 2003).

Assim, ao focar em sistemas e estruturas institucionais os pesquisadores poderão se beneficiar dessa perspectiva mais ampla de observação de normas sociais, bem como de arranjos legais e institucionais, especialmente em um contexto comparativo, porque as formas e causas da corrupção são muito diversas e variam dependendo das regiões e países. Da mesma forma, as sociedades e os grupos sociais em cada região e país também são diversos, onde as normas sociais são obviamente um aspecto fundamental na compreensão para a identificação das causas-raiz das práticas corruptas.

Desta forma, pesquisas futuras podem concentrar-se em estudar, por exemplo: (i) como os sistemas de controle gerencial são influenciados pela percepção dos gestores sobre o jeitinho brasileiro; (ii) analisar como os sistemas de controle gerencial são estruturados/modificados ajustarse os aspectos do jeitinho brasileiro; (iii) analisar como o jeitinho brasileiro é suprimido ou potencializado para ser utilizado a favor do negócio; e (iv) averiguar a dissonância cognitiva com a finalidade de identificar contradições e conflitos de identidade e a utilização do jeitinho brasileiro como esquiva a estas incoerências cotidianas no contexto organizacional.

Por fim, outro ponto que merece destaque é a realização de esforços para entender e analisar a corrupção. Desta forma, a pesquisa sobre corrupção poderia se beneficiar ao: (i) realizar esforços de coleta de dados que captem diferentes percepções do que se entende por práticas corruptas dentro de uma cultura; (ii) realizar estudos comparativos; (iii) analisar fontes alternativas de dados; e (iv) empregar ou combinar métodos de investigação (quantitativos e qualitativos), como por exemplo análise de discurso.

\section{REFERÊNCIAS}

Ackerman, S. R. (1978). Corruption: A study in political economy. Nova Iorque: Academic Press.

Albrecht, C., Malagueño, R., Holland, D., \& Sanders, M. (2012). A cross-country perspective on professional oversight, education standards and countries' perceived level of corruption. Cross cultural management: an international journal, 19(4), 433-454.

Araújo, R. F. d. (2014). A percepção de diferentes tipos de corrupção na ótica dos profissionais da contabilidade. (Mestrado em Ciências Contábeis Disssertação), Universidade de Brasília, Universidade Federal da Paraíba, Universidade Federal do Rio Grande do Norte, Natal.

Ashforth, B. E., \& Anand, V. (2003). The normalization of corruption in organizations. Research in organizational behavior, 25, 1-52.

Borini, F. M., \& Grisi, F. C. (2009). A corrupção no ambiente de negócios: survey com as micro e pequenas empresas da cidade de São Paulo. Revista de Administração-RAUSP, 44(2), 102117. 
Branco, M. C., \& Delgado, C. (2012). Business, social responsibility, and corruption. Journal of Public Affairs, 12(4), 357-365.

Brief, A. P., Buttram, R. T., \& Dukerich, J. M. (2001). Collective corruption in the corporate world: Toward a process model. Groups at work: Theory and research, 471, 499.

Chauí, M. d. S. (2000). Brasil: mito fundador e sociedade autoritária: Fundação Perseu Abramo.

Cosenza, J. P. (2015). Contabilidade criativa: as duas faces de uma mesma moeda. Pensar Contábil, $6(20)$.

Cosenza, J. P., \& Grateron, I. R. G. (2003). A auditoria da contabilidade criativa. Revista Brasileira de Contabilidade(143), 42-61.

Da Matta, R. (1984). O que faz o brasil, Brasil? (Vol. 7): Rocco Rio de Janeiro.

Emirbayer, M., \& Mische, A. (1998). What is agency? American journal of sociology, 103(4), 9621023.

Filgueiras, F. (2009). A tolerância à corrupção no Brasil: uma antinomia entre normas morais e prática social. Opinião Pública, 15(2), 386-421.

Fisher, J. (1995). Contingency-based research on management control systems: categorization by level of complexity. Journal of accounting literature, 14, 24.

Flach, L. (2012). O jeitinho brasileiro: analisando suas características e influências nas práticas organizacionais. Gestão \& Planejamento-G\&P, 13(3).

Furtado, C. (1999). O longo amanhecer: reflexões sobre a formação do Brasil: Paz e terra.

Gadea, J. A. L., \& Gastón, S. C. (1999). Contabilidad creativa: Civitas.

Geertz, C. (1989). Uma descrição densa: por uma teoria interpretativa da cultura. A interpretação das culturas, 1, 3-21.

GLOBO, O. (2014). 'Jeitinho brasileiro': 82\% acham que maioria pretende tirar vantagem, diz pesquisa.

Gomes, R. (1977). Crítica da razão tupiniquim.

Granovetter, M. (2006). A construção social da corrupção. Política \& Sociedade, 5(9), 11-38.

Hofstede, G. (2001). Culture's consequences: Comparing values, behaviors, institutions and organizations across nations: Sage publications.

Hofstede, G., \& Bond, M. H. (1988). The Confucius connection: From cultural roots to economic growth. Organizational Dynamics, 16(4), 5-21.

Holanda, S. B. d. (1936). Raízes do Brasil, 2 a reimpressão. Companhia das Letras, São Paulo.

Jones, G. R. (2010). Teoria das organizações. Tradução Luciane Pauleti e Daniel Vieira. $6^{a}$ ed. São Paulo: Pearson Education do Brasil. 
Kwok, C. C., \& Tadesse, S. (2006). National culture and financial systems. Journal of International Business Studies, 37(2), 227-247.

Lang, J. J. B. (1998). De la contabilidad creativa al delito contable. Partida doble(85), 33-39.

Mayoral, J. M. (2000). Los limites de la información financeira. Artigo apresentado na Universidade de Extremadura. Espanha.

Motta, F. C. P., \& Alcadipani, R. (1999). Jeitinho brasileiro, controle social e competição. Revista de Administração de Empresas, 39(1), 6-12.

Oliver, C. (1991). Strategic responses to institutional processes. Academy of management review, 16(1), 145-179.

Pedroso, J. P. P., Massukado-Nakatani, M. S., \& Mussi, F. B. (2009). A relação entre o jeitinho brasileiro e o perfil empreendedor: possíveis interfaces no contexto da atividade empreendedora no Brasil.

Ratner, C. (1991). Vygotsky's sociohistorical psychology and its contemporary applications: Springer Science \& Business Media.

Singer, P. (1998). De dependência em dependência: consentida, tolerada e desejada. Estudos Avançados, 12(33), 119-130.

Treviño, L. K., \& Weaver, G. R. (2003). Managing ethics in business organizations: Social scientific perspective: Stanford University Press.

Vaz, H. C. d. L. (1988). Escritos de filosofia II: ética e cultura (Vol. 3): Edicoes Loyola.

Zanella, A. V. (2008). Escolarização formal e cidadania: possíveis relações, relações possíveis? In A. F. e. a. SILVEIRA (Ed.), Cidadania e participação social (pp. 84-91). Online: Rio de Janeiro: Centro Edelstein de Pesquisas Sociais. 